\title{
Effect of a specific iron chelating agent on animal models of inflammation
}

\author{
D A VID R. BLAKE, ${ }^{1}$ NICOLAS D. HALL, ${ }^{1}$ PAUL A. B ACON, ${ }^{1}$ \\ PAUL A. DIEPPE, ${ }^{2}$ BARRY HALLIWELL, ${ }^{3}$ AND \\ JOHN M. C. GUTTERIDGE
}

From the ${ }^{1}$ Royal National Hospital for Rheumatic Diseases, Upper Borough Walls, Bath BA1 1RL; the ${ }^{2}$ Department of Rheumatology, Bristol Royal Infirmary, Bristol BS2 $8 \mathrm{HW}$; the ${ }^{3}$ Department of Biochemistry, King's College, London WC2R 2 LS; and the ${ }^{4}$ National Institute for Biological Standards and Control, Holly Hill, London NW3 6RB

SUMMARY Iron is an important catalyst of oxidative radical reactions and promotes the formation of the hydroxyl radical from the superoxide anion radical and hydrogen peroxide. The stimulatory effect of the hydroxyl radical on lipid peroxidation prompted the speculation that free iron may directly promote inflammation and that iron chelating agents may have useful anti-inflammatory properties. This hypothesis is tested in animal models of inflammation with a specific iron chelating agent, desferrioxamine. At low doses $(6.6 \mathrm{mg} / \mathrm{kg})$ intraperitoneal desferrioxamine stimulated the induction of acute foot pad swelling in rats by monosodium urate but at higher doses (above 200 $\mathrm{mg} / \mathrm{kg}$ ) it suppressed this inflammatory reaction. A similar anti-inflammatory effect was observed in carrageenan-induced foot pad swelling. In guinea-pigs in which a Glynn-Dumonde synovitis was induced with bovine gammaglobulin, desferrioxamine $(100 \mathrm{mg} / \mathrm{kg})$ stimulated the acute inflammatory induction phase of this chronic allergic monoarthritis model. Repeated administration of desferrioxamine $(100 \mathrm{mg} / \mathrm{kg})$ from the seventh to the twelfth day after intra-articular challenge with bovine gammaglobulin markedly depressed the chronic inflammatory phase. In-vitro experiments suggest that desferrioxamine inhibits iron-catalysed lipid peroxidation when it is poorly saturated with iron, but loses this effect when it is iron saturated. Such an effect may explain our results with desferrioxamine in the animal studies and suggests that effective iron chelation and its removal may modify the inflammatory process in man.

Iron is an important catalyst in biological systems. Its easy access to 2 oxidation states, iron II and iron III, allows it to co-ordinate electron donors and to participate in redox processes. However, this property is potentially hazardous, since reactions involving oxygen favour a univalent reduction pathway which leads to the formation of unstable intermediates with unpaired electrons-free radicals. ${ }^{1}$

The superoxide radical $\left(\mathrm{O}_{2}{ }^{-}\right)$, the first univalent reduction product of oxygen, is released along with hydrogen peroxide during phagocytosis by polymorphonuclear leucocytes and macrophages. ${ }^{2}$ In the presence of traces of free iron salts, superoxide and hydrogen peroxide can react together to produce

Accepted for publication 12 January 1982.

Correspondence to Dr D. Blake, Royal National Hospital for Rheumatic Diseases, Bath BA1 1RL. the highly toxic hydroxyl radical $(\mathrm{OH} \cdot)^{3}$ This reaction can be expressed as follows:

$$
\mathrm{Fe}^{2+}+\mathrm{H}_{2} \mathrm{O}_{2} \rightarrow \mathrm{OH} \cdot+\mathrm{Fe}^{3+}+\mathrm{OH}^{-}
$$

Reaction $(a)$ is referred to as the Fenton reaction. The iron II required for the reaction is thought to be derived from the more stable iron III form by a reductive process involving superoxide:

$$
\mathrm{Fe}^{3+} \text { complex }+\mathrm{O}_{2}^{-} \rightarrow \mathrm{Fe}^{2+} \text { complex }+\mathrm{O}_{2}
$$

with a net result:

$$
\mathrm{H}_{2} \mathrm{O}_{2}+\mathrm{O}_{2}^{-} \rightarrow \mathrm{O}_{2}+\mathrm{OH}^{-}+\mathrm{OH}^{-}
$$

Reaction $(c)$ is referred to as the iron catalysed Haber-Weiss reaction.

The toxicity of superoxide and hydrogen peroxide may therefore involve their conversion to the hydroxyl radical, a reaction which in turn will depend on the amount of catalytic iron available. 
The NADPH oxidase responsible for the production of superoxide and hydrogen peroxide is located in the cell membrane. ${ }^{2}$ Membranes consist of organised bilayers which contain substantial amounts of polyunsaturated fatty acids. These fatty acids are particularly susceptible to free radical attack. Following hydrogen abstraction and oxygen uptake peroxy and alkoxy free radicals are formed which continue a chain reaction, resulting in destruction of the fatty acid and formation of lipid peroxides. ${ }^{4}$ Lipid peroxidation therefore inevitably leads to disruption of cell and organelle membranes, with release of their compartmentalised contents. ${ }^{5}$ Such damage to lysosomes can amplify destructive processes by the release of hydrolytic enzymes. This may help to perpetuate inflammation.

Desferrioxamine, a trihydroxamic acid, is an iron chelating agent with an extremely high binding affinity for iron, complexing one molecule of iron III per molecule of desferrioxamine. In-vitro studies have confirmed that it will inhibit the iron catalysed generation of the hydroxyl radical (the Haber-Weiss reaction) and lipid peroxidation. ${ }^{6}$ These observations have led us to speculate that iron may have a direct role in inflammation and that iron chelating agents may have anti-inflammatory properties. In the present studies we have evaluated (1) the antiinflammatory effect of desferrioxamine in a number of animal models of inflammation, including urate and carrageenan induced paw swelling in rats and Glynn-Dumonde synovitis in guinea-pigs, and (2) the effect of variably iron saturated desferrioxamine on the rate of iron catalysed lipid peroxidation in vitro.

\section{Materials and methods}

ANIMAL MODELS OF INFLAMMATION

A monosodium urate monohydrate suspension was made according to the method of Seegmiller et al. ${ }^{7}$ The suspension was sonicated for one minute prior to injection. Desferrioxamine B (Desferal) was generously provided by Ciba Laboratories, Horsham, West Sussex. The drug was dissolved in sterile phosphate buffered saline $\mathrm{pH} 7 \cdot 4$ (PBS) within 24 hours of each injection.

Acute inflammation model. Female Lister hooded rats (weight $150 \mathrm{~g}$ ) were injected cutaneously into the left foot pad with $0.2 \mathrm{ml}$ of either (i) $1 \% \mathrm{w} / \mathrm{v}$ monosodium urate monohydrate crystal suspension in PBS, or (ii) type 4 lambda carrageenan in PBS. Direct measurement of foot circumference was related to the uninjected foot and the left foot prior to injection. Measurements were made in a series of experiments over a 2-24 hour period in rats receiving variable doses of intraperitoneal (IP) desferriox- amine or PBS one hour prior to the inflammatory stimulus.

Chronic inflammation model. A Glynn-Dumonde synovitis was established in guinea-pigs with bovine gammaglobulin as antigen. Female Duncan-Hartley guinea-pigs $(500 \mathrm{~g})$ were sensitised to $5 \mathrm{mg}$ bovine gammaglobulin (BGG, Cohn Fraction II, Sigma) emulsified in Freund's complete adjuvant (Gibco: $0.5 \mathrm{ml}$ given as multiple subcutaneous injections). After 28 days they were challenged with $1 \mathrm{mg}$ BGG in $0.05 \mathrm{ml}$ PBS by intra-articular (IA) injection to the right knee. A control group of animals received IA PBS only. Serial measurements of lateral joint diameter of both injected (right) and control (left) knees were made with a vernier scale caliper. These assessments were carried out over a 28 -day period by a 'blind' observer, and the results were expressed as the difference in diameter between injected and control knees. Desferrioxamine $(100 \mathrm{mg} / \mathrm{kg})$ was administered by IP injection as indicated in the 'Results' section. Data were parametric, and therefore Student's $t$ test was used to compare groups.

LIPID PEROXIDATION (IN VITRO)

Bovine brain phospholipid liposomes were prepared and their peroxidation, induced by $38 \mu \mathrm{M}$ ascorbate was measured by the thiobarbituric acid method as? described by Gutteridge. ${ }^{8}$ Each reaction mixture contained $2.5 \mathrm{mg}$ of phospholipid in $0.15 \mathrm{M} \mathrm{NaC} 1$ prepared in Chelex-treated water $\mathrm{pH} 7 \cdot 4$. Iron was added as ammonium ferric sulphate to both lipids and desferrioxamine.

\section{Results}

ANIMAL MODELS OF INFLAMMATION

\section{Acute inflammation model}

$1 \%$ Monosodium urate monohydrate crystal to rat foot pad. Three groups of rats received $1 \mathrm{mg}, 10 \mathrm{mg}$, or $30 \mathrm{mg}$ desferrioxamine IP one hour prior to challenge with urate (see 'Methods'). Eight control rats received IP PBS only. Foot pad circumference was measured at 4 and at 24 hours (see Table 1). Rats receiving $1 \mathrm{mg}$ desferrioxamine showed a significant increase in swelling compared with the controls at 4 hours $(p<0.05)$, while $30 \mathrm{mg}$ desferrioxamine had a significant anti-inflammatory effect $(p<0 \cdot 05)$. The foot pads of rats receiving $1 \mathrm{mg}$ were considerably redder, with the swelling extending up the hind limb.

In a separate experiment 2 groups of rats received $0.2 \mathrm{mg}$ or $60 \mathrm{mg}$ IP desferrioxamine as above (Table 1). The $0.2 \mathrm{mg}$ dose had no significant effect on foot pad swelling, while the $60 \mathrm{mg}$ dose had a pronounced anti-inflammatory effect $(\mathrm{p}<0 \cdot 001)$. 
Table 1 Effect of variable doses of desferrioxamine on monosodium urate induced foot pad swelling in rats

\begin{tabular}{|c|c|c|c|c|c|c|c|c|}
\hline & \multicolumn{4}{|l|}{$4 h$} & \multicolumn{4}{|c|}{$24 h$} \\
\hline & No. & Mean* & $S E M$ & Significance $(p<)$ & No. & Mean* & $S E M$ & Significance $(p<)$ \\
\hline \multicolumn{9}{|l|}{ Experiment 1} \\
\hline Control & 8 & 0.31 & 0.04 & & 8 & 0.29 & 0.03 & \\
\hline $1 \mathrm{mg}$ Desferrioxamine & 6 & 0.47 & 0.04 & 0.05 & 6 & 0.27 & 0.03 & NS \\
\hline $10 \mathrm{mg}$ & 6 & $0 \cdot 40$ & 0.04 & NS & 6 & 0.23 & 0.04 & NS \\
\hline \multirow{2}{*}{\multicolumn{9}{|c|}{ Experiment 2}} \\
\hline & & & & & & & & \\
\hline Control & 15 & 0.27 & 0.03 & & & & & \\
\hline 0.2 $\mathrm{mg}$ Desferrioxamine & 15 & 0.24 & 0.03 & NS & & & & \\
\hline $60 \mathrm{mg}$ & 14 & $0 \cdot 11$ & 0.02 & 0.001 & & & & \\
\hline
\end{tabular}

-Values expressed as mean increase in circumference (in centimetres), relating to circumference of foot pad prior to injection with urate crystals. SEM=standard error of mean. NS= not significant.

$1 \%$ Carrageenan to rat foot pads. Two groups of rats received either $1 \mathrm{mg}$ or $60 \mathrm{mg}$ desferrioxamine one hour prior to challenge with carrageenan (see 'Methods'). Control rats received IP PBS only. Serial measurements were made at 4,6 , and 24 hours (see Table 2). The $60 \mathrm{mg}$ dose had a significant antiinflammatory effect at all 3 time points, while the 1 $\mathrm{mg}$ dose showed/a/significant/anti-inflammatory effect at 24 hours only. Foot pad swelling in this experiment was considerably more than that induced by urate crystals, which might well have masked any potential proinflammatory effect of the $1 \mathrm{mg}$ dose.

Desferrioxamine did not induce any discernible short-term systemic effects at any dose. Eighteen animals (3 groups of 6) receiving $1 \mathrm{mg}, 10 \mathrm{mg}$, or 30 $\mathrm{mg}$ IP desferrioxamine were observed for a further 2 weeks, and again no animal appeared to suffer any adverse effects. No animal receiving $60 \mathrm{mg}$ of IP desferrioxamine suffered peritoneal irritation when assessed at 4 hours.

\section{Chronic inflammation model}

Glynn-Dumonde synovitis. Three groups of guineapigs presensitised to BGG were used to assess the effect of desferrioxamine on early and established Glynn-Dumonde synovitis. Control animals (group $A, n=6)$ were injected with PBS alone ( $0.05 \mathrm{ml} \mathrm{IA})$. $A$ second group (group $B, n=12$ ) received an IA challenge of $1 \mathrm{mg} \mathrm{BGG}$ in $0.05 \mathrm{ml}$ PBS, and the final group (group $C, n=6$ ) received both IA BGG and a single IP injection of desferrioxamine $(100 \mathrm{mg} / \mathrm{kg})$. Lateral knee diameters were measured over 7 days and the difference between injected and control joints plotted against time (Fig. 1). Intra-articular injection of PBS caused only a mild transient swelling. Joints injected with BGG showed a large increase in diameter which peaked at day 1-2 but which settled to chronic swelling after day 4 . Coadministration of IP desferrioxamine caused significantly greater swelling than that in the animals given BGG alone (day 2, p $<0.01$; day $4, \mathrm{p}<0.05$; day 7 , $\mathrm{p}<0.025)$. The desferrioxamine-treated animals also displayed a far greater erythematous reaction over the injected knee than either of the control groups. On day 7 group B was split into 2 subgroups. The first $(B 1, n=6)$ received IP PBS daily for 6 days, the second $(B 2, n=6)$ received IP desferrioxamine $(100$ $\mathrm{mg} / \mathrm{kg}$ ) daily for 6 days. Results are presented in Fig.1. The control animals maintained a chronic swelling of the BGG-injected knee until day 28. The desferrioxamine-treated group showed a suppression of this swelling, which was statistically significant on days $14(\mathrm{p}<0.01)$ and $17(\mathrm{p}<0.05)$. After this time the effect of the desferrioxamine treatment period (days 7-12) wore off, and the difference between treated and control animals was lost. No acute exacerbation of the inflammatory reaction in the injected knees as seen in group $\mathrm{C}$ was noted in this part of the experiment. However, the desferrioxamine-treated guinea-pigs (group B2) did show increased redness and swelling of the fore feet,

Table 2 Effect of variable doses of intraperitoneal desferrioxamine on lambda carrageenan induced foot pad swelling in rats

\begin{tabular}{|c|c|c|c|c|c|c|c|c|c|c|c|c|}
\hline & \multicolumn{4}{|l|}{$4 h$} & \multicolumn{4}{|l|}{$6 h$} & \multicolumn{4}{|l|}{$24 h$} \\
\hline & No. & Mean* & $S E M$ & $\begin{array}{l}\text { Significance } \\
(p<)\end{array}$ & No. & Mean* & $S E M$ & $\begin{array}{l}\text { Significance } \\
(p<)\end{array}$ & No. & Mean* & $S E M$ & $\begin{array}{l}\text { Significance } \\
(p<)\end{array}$ \\
\hline $\begin{array}{l}\text { Control } \\
1 \mathrm{mg} \text { Desferrioxamine } \\
60 \mathrm{mg}\end{array}$ & $\begin{array}{l}22 \\
20 \\
21\end{array}$ & $\begin{array}{l}0.46 \\
0.42 \\
0.30\end{array}$ & $\begin{array}{l}0.05 \\
0.04 \\
0.02\end{array}$ & $\begin{array}{l}\text { NS } \\
.001\end{array}$ & $\begin{array}{l}20 \\
18 \\
19\end{array}$ & $\begin{array}{l}0.55 \\
0.54 \\
0.45\end{array}$ & $\begin{array}{l}0.03 \\
0.03 \\
0.02\end{array}$ & $\begin{array}{l}\text { NS } \\
.005\end{array}$ & $\begin{array}{l}18 \\
16 \\
17\end{array}$ & $\begin{array}{l}0 \cdot 43 \\
0 \cdot 31 \\
0 \cdot 35\end{array}$ & $\begin{array}{l}0.02 \\
0.03 \\
0.02\end{array}$ & $\begin{array}{l}0.001 \\
0.02\end{array}$ \\
\hline
\end{tabular}

*Values expressed as mean increase in circumference (in centimetres), relating to circumference of foot pad prior to injection with lambda carrageenan. 


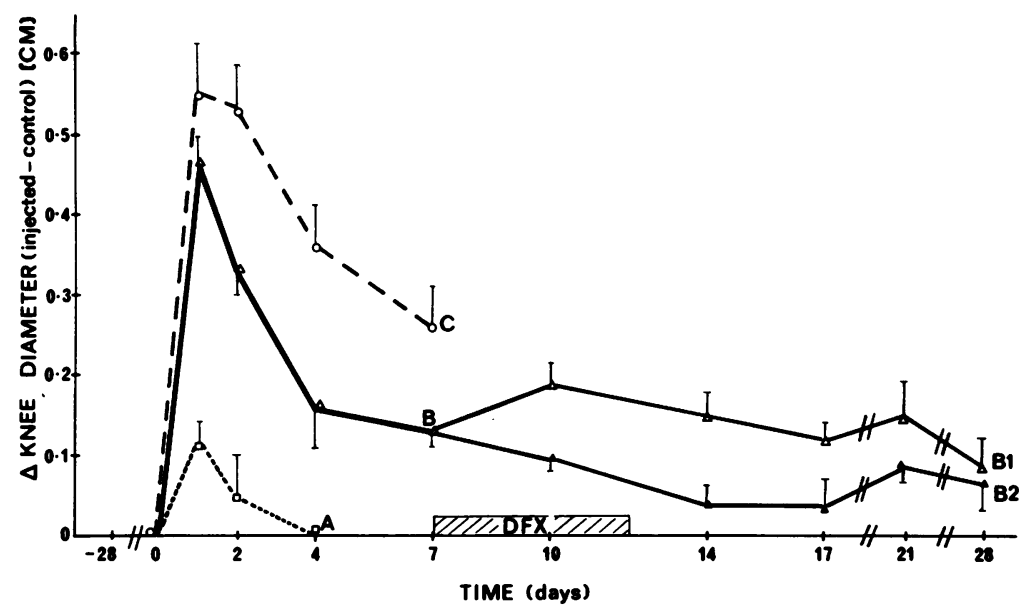

Fig. 1 Effect of desferrioxamine on acute and chronic phases of Glynn-Dumonde synovitis in guinea-pigs. Twenty-four guinea-pigs sensitised to $B G G$ on day -28 were treated as follows: on day 0 , group $A(n=6)$ received $1 A P B S(0.05 \mathrm{ml})$, group $B(n=12)$ received IA BGG $(1 \mathrm{mg}$ in $0.05 \mathrm{ml} P B S)$, and group $C(n=6)$ received IA BGG $(1 \mathrm{mg}$ in $0.05 \mathrm{ml} P B S)$ and IP desferrioxamine $(100 \mathrm{mg} / \mathrm{kg})$. On day $7 \mathrm{group} B$ was divided into $B 1(n=6)$, which received IP PBS daily for 6 days, and $B 2$ $(n=6)$, which received IP desferrioxamine $(100 \mathrm{mg} / \mathrm{kg})$ daily for a similar period. The animals were assessed over the time scale indicated, and the results are expressed as the mean difference in knee diameter (injected-control) \pm one standard error of the mean. The group data were compared at various time points by Student'st test: group C significantly worse than group $B$ on day $2(p<0.01)$, day $4(p<0.05)$, and day $7(p<0.025)$; group B2 significantly better than group B1 on day $14(p<0.01)$ and day $17(p<0.05)$.

the site of the original sensitising injections of BGG and Freund's complete adjuvant.

\section{LIPID PEROXIDATION (IN VITRO)}

Peroxidation of phospholipid liposomes can be induced by ascorbate in a reaction which is inhibited by desferrioxamine (Table 3 ). Previous studies have shown that this is due to traces of iron present in the reagent systems. ${ }^{6}$ Addition of a ferric salt greatly enhanced the ascorbate-dependent peroxidation. When desferrioxamine was added to the lipid before the iron salt, it acted as an effective inhibitor of peroxidation. This inhibitory activity appeared to be greater than that simply accounted for by its known
1:1 molar ferric iron chelating properties. Desferrioxamine mixed with ferric iron before addition to the lipid showed that protective activity is lost when saturation is reached. An equimolar mixture of desferrioxamine and iron III salt showed inhibitory activity toward the ascorbate catalysed peroxidation, suggesting that the desferrioxamine had not been fully saturated under the conditions used for preparation.

\section{Discussion}

Desferrioxamine is a chelating agent with an extremely high activity and specificity for Fe III

Table 3 Effect of desferrioxamine on iron-catalysed lipid peroxidation. Rate of peroxidation (TBA-reactivity at 532 nm) after $1 \mathrm{~h}$ incubation at $37^{\circ} \mathrm{C}$

\begin{tabular}{llll}
\hline $\begin{array}{l}\text { Additions to } 0.009 \mathrm{M} \text { phosphate } \\
\text { buffered liposomes } \mathrm{pH} 7.4\end{array}$ & $\begin{array}{l}28 \mu \mathrm{M} \text { ascorbate added } \\
\text { to the iron* }\end{array}$ & $\begin{array}{l}77 \mu M \text { desferrioxamine added to the lipid } \\
\text { before addition of iron * followed by } 38 \mu M \\
\text { ascorbate }\end{array}$ & $\begin{array}{l}77 \mu M \text { desferrioxamine complexed with } \\
\text { iron III* before addition to lipid followed by } \\
38 \mu M \text { ascorbate }\end{array}$ \\
\hline Blank (ascorbate $28 \mu \mathrm{M}+$ & & & - \\
desferrioxamine $77 \mu \mathrm{M})$ & 0.04 & - & - \\
Control (ascorbate $28 \mu \mathrm{M})$ & 0.25 & 0.05 & 0.06 \\
Test 1. $7.7 \mu \mathrm{M}$ iron III & 0.47 & 0.06 & 0.06 \\
Test 2. $38 \mu \mathrm{M}$ iron III & 0.72 & 0.12 & 0.14 \\
Test $3.77 \mu \mathrm{M}$ iron III & 0.94 & 0.43 & 0.94 \\
Test $4.154 \mu \mathrm{M}$ iron III & 1.20 &
\end{tabular}

"Values given in tests $1-4$.

Results are expressed as the mean of 3 separate assays, which were highly reproducible. Concentrations given are the final concentrations in the reaction mixture. 
demonstrated by a stability constant of $10^{31}$. In contrast its stability constants for zinc, calcium, and magnesium are much lower $\left(10^{11}, 10^{2}\right.$, and $10^{4}$ respectively). The lack of effect of desferrioxamine on other trace elements differentiates it from chelating agents such as EDTA, which can increase the excretion of other metals, particularly zinc. ${ }^{9}$

The specificity of the chelating effect of desferrioxamine and the anti-inflammatory effects of this drug on the 3 models described therefore support the original hypothesis that iron may have an important role in the initiation and maintenance of inflammation. However, the short term stimulatory effect of desferrioxamine on inflammation needs further explanation.

Lipid peroxidation is stimulated by both free $^{810}$ and complexed ${ }^{1112}$ iron, though the effect of the latter is variable. ${ }^{11}$ With the iron-binding protein lactoferrin this variability has been shown to relate to the degree of iron saturation. Apolactoferrin, or the partially iron-saturated protein, is an effective inhibitor of hydroxyl radical formation and lipid peroxidation, ${ }^{11}$ whereas fully iron-saturated lactoferrin can catalyse hydroxyl radical formation. ${ }^{13}$ Similarly, desferrioxamine inhibits iron-catalysed lipid peroxidation when poorly saturated with iron. This protection appears to be greater than can be accounted for by its iron chelation properties and may suggest a radical scavenging role for this drug.

Mechanisms such as these may in part explain our results with desferrioxamine in the animal studies. The trapping of iron as part of a poorly saturated desferrioxamine complex would inhibit ironcatalysed damage and lipid peroxidation and thereby suppress the inflammatory response. This inhibitory effect would be expected to occur if relatively high doses of desferrioxamine were available at the inflammatory site or if the ferrioxamine had been excreted. In contrast, low doses of desferrioxamine would rapidly become iron saturated and lose its protecting properties against iron catalysed lipid peroxidation.

The results of these experiments suggest that effective iron chelation and its removal may prove a useful way of modifying the inflammatory process in man. It may be particularly appropriate to the treatment of rheumatoid disease, where iron is concentrated in the synovial membrane ${ }^{14}$ and where there are large numbers of activated polymorphonuclear cells releasing oxygen free radicals, but no free radical scavengers, within the synovial fluid. ${ }^{15}$

\section{References}

1 Fridovitch I. Superoxide dismutase. In: Meister A, ed. Advances in Enzymology. London: Interscience, 1974; 41: 35-97.

2 Babior B M. Oxygen dependent microbial killing by phagocytes. N Engl J Med 1978; 298: 659-68.

3 Halliwell B. The biological effects of the superoxide radical and its products. Bull Eur Physiopathol Respir 1981; 17: 21-8.

4 Pryor W A. The role of free radical reactions in biological systems. In: Pryor W A, ed. Free Radicals in Biology. New York: Academic Press, 1976: 1: 1-49.

5 Tappel A L. Lipid peroxidation and fluorescent molecular damage to membranes. In: Trump B F, Arstila A V, eds. Pathobiology of Cell Membranes. New York: Academic Press, 1975; 1: 145-72.

6 Gutteridge J M C, Richmond R, Halliwell B. Inhibition of the iron catalysed formation of hydroxyl radicals from superoxide and of lipid peroxidation by desferrioxamine. Biochem J 1979; 184: 469-72.

7 Seegmiller J E, Howell R R, Malawista S E. The inflammatory reaction to sodium urate. JAMA 1962; 180: 469-75.

8 Gutteridge J M C. Measurement of malondialdehyde in peroxidised ox-brain phospholipid liposomes. Anal Biochem 1977; 82: 76-82.

9 17th Annual Meeting of Swiss Haematological Society. Results with desferrioxamine in pathological iron deposition: a round table discussion. Chairman, Moeschlin S. Schweiz Med Wochenschr 1962; 92: 1295-306.

10 Halliwell B, Richmond R, Wong S F, Gutteridge J M C. The biological significance of the Haber-Weiss reaction. In: Bannister W H, Bannister J V, eds. Biological and Clinical Aspects of Superoxide and Superoxide Dismutase. New York: Elsevier/North Holland, 1980. 11B: 32-40.

11 Gutteridge J M C, Paterson S K, Segal A W, Halliwell B. Inhibition of lipid peroxidation by the iron binding protein lactoferrin. Biochem J 1981; 199: 259-61.

12 Wills E D. Mechanisms of lipid peroxide formation in animal tissues. Biochem J 1966; 99: 667-76.

13 Ambruso D R, Johnston R B. Lactoferrin enhances hydroxyl radical production by human neutrophils, neutrophil particulate fractions, and an enzymatic generating system. J Clin Invest 1981; 67: 352-60.

14 Muirden K D, Senator G B. Iron in the synovial membrane in rheumatoid arthritis and other joint diseases. Ann Rheum. Dis 1968; 27: 34-48.

15 Blake D R, Hall N D, Treby D A, Halliwell B, Gutteridge J M C. Protection against superoxide and hydrogen peroxide in synovial fluid from rheumatoid patients. Clin Sci 1981; 61: 483-6. 